\title{
Sensitivity difference to insecticides of a riverine caddisfly, Cheumatopsyche brevilineata (Trichoptera: Hydropsychidae), depending on the larval stages and strains
}

\author{
Atsushi Yokoyama*, Kazuhisa Ohtsu, Takashi Iwafune, Takashi Nagai, \\ Satoru IshiHARA ${ }^{\dagger}$, Yuso Kobara, Takeshi Horio and Shozo ENDO ${ }^{\dagger \dagger}$ \\ National Institute for Agro-Environmental Sciences, 3-1-3 Kannondai, Tsukuba, Ibaraki 305-8604, Japan \\ ${ }^{\dagger}$ Agricultural Chemicals Inspection Station, Food and Agricultural Materials Inspection Center, \\ 2-772 Suzuki-cho, Kodaira, Tokyo 187-0011, Japan \\ ${ }^{\dagger}$ Bio-oriented Technology Research Advancement Institution Tokyo Office, National Agriculture and Food Research Organization, \\ 3-18-19 Toranomon, Minato-ku, Tokyo 105-0001, Japan
}

(Received August 11, 2008; Accepted September 9, 2008)

\begin{abstract}
To determine sensitivity to fenitrothion (MEP), fenobucarb (BPMC) and imidacloprid (IMI) in each larval instar of Cheumatopsyche brevilineata, we carried out 48-hr acute toxicity tests using strains $\mathrm{M}$ and $\mathrm{K}$ originating from an urban river and an irrigation canal, respectively. First instar was the most sensitive stage to all three insecticides whereas fifth instar was the most insensitive in both strains. Larvae of strain $\mathrm{K}$ were significantly more insensitive to MEP through larval growth and to BPMC in second or later instars than larvae of strain M; however, sensitivity to IMI did not differ significantly between strains. C Pesticide Science Society of Japan
\end{abstract}

Keywords: caddisfly, riverine insects, different larval instars, insecticide, sensitivity.

\section{Introduction}

Populations of aquatic organisms in nature generally consist of a mixture of life stages with different sensitivities to a chemical. Acute toxicity tests performed at the most sensitive life stage possibly overestimate the effects of chemicals on populations. ${ }^{1)}$ A series of acute toxicity tests performed at different life stages can be useful to determine the profile of sensitivity in a life cycle, and to appropriately assess populationlevel effects on aquatic organisms.

Aquatic organisms are known to tend to be more sensitive to chemicals in their earlier life stages. ${ }^{2)}$ The freshwater crustacean Asellus aquaticus became more resistant to cadmium as its juveniles became older. ${ }^{3)}$ Older larval stages of the midge Chironomus tentans was also more resistant to copper than younger stages. ${ }^{4)}$ In some aquatic insects, such as blackfly and caddisfly, sensitivities to several organophosphate insecticides decreased with larval growth; ${ }^{5-7)}$ however, the ten-

\footnotetext{
* To whom correspondence should be addressed.

E-mail: ayoko@niaes.affrc.go.jp

Published online December 30, 2008

(C) Pesticide Science Society of Japan
}

dency for sensitivity to decrease with growth is not observed in all organisms. ${ }^{8-11)}$ In the freshwater shrimp Paratya compressa improvisa, sensitivity to an organophosphate, fenitrothion, did not change until 60 days after hatching. ${ }^{8)}$ The earliest age class of the amphipod Hyalella azteca was most insensitive to an organophosphate, diazinon. ${ }^{9)}$ Nishimoto ${ }^{10)}$ indicated that older larval stages of a case-making caddisfly, Neophylax sp. NA., were more sensitive to fenitrothion.

A riverine caddisfly, Cheumatopsyche brevilineata, is distributed widely in Japan and the larvae inhabit irrigation canals, streams and rivers. In such flowing water, the caddisfly is among the most important benthoses because of their large biomass and abundance. ${ }^{12}$ This species undergoes complete metamorphosis, developing through four distinct stages: egg, larva, pupa and adult. Larvae of $C$. brevilineata ingest drifted algae and detritus and develop through five larval stages in flowing water. ${ }^{12)}$ Yagi and Sasakawa ${ }^{12)}$ also reported that several instars coexisted all year around in the Kamo River, Kyoto, Japan. Given the overlap between its habitat and areas under rice cultivation, it is ecologically meaningful to use the caddisfly as a test organism to assess the impact of paddy insecticides on riverine environments; however, it remains unclear whether sensitivity to insecticides changes during larval 
growth and whether sensitivity differs among populations with different ecological backgrounds.

The purpose of this study is to determine the sensitivity of each instar of $C$. brevilineata to three paddy insecticides with different modes of action, using two strains collected from an urban river and an irrigation canal, respectively.

\section{Materials and Methods}

\section{Test organism and rearing conditions}

Strain M originated from a population of $C$. brevilineata in the upper reaches of the Miya River, which flows through the city of Yokohama, Kanagawa, Japan. The catchment of the river is covered by parks or urban areas, and no agricultural land exists there; therefore, we assumed that the river's exposure to paddy pesticides is negligible. Strain K originated from the caddisfly population in the Kokura River, which flows through a paddy region in Ishioka City, Ibaraki prefecture. Strains M and K were established on June 6 and September 6, 2004, respectively.

We maintained both strains in separate rooms $\left(20^{\circ} \mathrm{C}\right.$, a photoperiod of 18-hr light : 6-hr dark) according to the method of Yokoyama et al. ${ }^{13)}$ as follows. Briefly, larvae were kept in an acrylic rearing container in which the water was continuously stirred by a magnetic stirrer and aerated. The larvae were fed commercial fish food daily ad libitum. Water in the rearing container was replaced every 2 days. Emerged adults were transferred to an oviposition aquarium filled with water to a depth of $10 \mathrm{~cm}$. Some square oviposition substrates (stone, brick or polyvinyl-chloride blocks) were placed on the bottom of the aquarium. Females oviposited egg masses on the submerged substrates under lentic conditions. The substrates and attached egg masses were removed every day and placed in a new rearing container to provide the next generation. This rearing system supported the full life cycle year-round, and enabled each larval instar to be collected for toxicity experiments. The larvae were sorted into instar classes by head width $^{12)}$ before each acute toxicity test.

\section{Chemicals}

We investigated the acute toxicity of three insecticides: an organophosphate: fenitrothion (MEP), a carbamate: fenobucarb (BPMC) and a neonicotinoid: imidacloprid (IMI). The mode of action of the three insecticides is as follows: MEP and BPMC inactivate acetylcholinesterase in the insect nervous system; ${ }^{14)}$ IMI acts as a partial agonist of nicotinic acetylcholine receptor. ${ }^{15)}$ Based on annual shipments of active ingredients, ${ }^{16)}$ these insecticides are commonly still in use on agricultural land, including paddy fields in Japan. We prepared stock and serial dilutions of these insecticides in acetone, and preserved them at $4^{\circ} \mathrm{C}$ in the dark. All chemicals were of analytical grade and were purchased from Wako Pure Chemical Ind., Ltd. (Osaka, Japan).

\section{Acute toxicity tests}

Conditions of acute toxicity tests using each larval instar are summarized in Table 1 . All toxicity tests were conducted at $20^{\circ} \mathrm{C}$. Before the preparation of test solutions, dechlorinated tap water was filtered through a membrane filter $(0.22-\mu \mathrm{m}$ pores). To prepare a series of nine concentrations in the test solutions, we added appropriate volumes of insecticide stock solution to the dechlorinated tap water. The final concentration of acetone in test solutions did not exceed $0.1 \%(\mathrm{v} / \mathrm{v})$. Twenty larvae were used for each concentration and for the control. Test solutions were not changed during the test. No food was added to any of the test vessels.

Acute toxicity tests using first-instar larvae less than $24 \mathrm{hr}$ old were conducted by the method of Yokoyama et al. ${ }^{13)}$ Polystyrene 48-well dishes were used as test vessels. First-instar larvae were placed individually in each well containing test solution. Because newly hatched larvae swim towards light, we illuminated them continuously from beneath with white fluorescent light ( $c a$. 4000 lux) to avoid trapping them at the water surface. Toxicity tests with first-instar larvae were conducted under lentic conditions.

The test conditions of first instar were slightly modified for second- and third-instar larvae: larger test vessels were used and the volume of test solution was increased. Test vessels containing test solution and larvae were placed on a rotary shaker and the test solution was agitated during the experiment.

In acute toxicity tests with fourth- and fifth-instar larvae, test conditions were further modified and conditions became more lotic. A rotary flowing water system according to Tada ${ }^{17)}$ was modified and applied to these experiments. One day prior to the start of exposure, 10 larvae were placed in each glass beaker containing $400 \mathrm{ml}$ (for fifth instar) or 200 $\mathrm{ml}$ (for fourth instar) of dechlorinated tap water and glass beads as bottom materials. The water was continuously stirred with a magnetic stirrer during the experiment. Larvae constructed fixed tubular retreats with glass beads during the acclimation. Dead or weakened larvae were removed from beakers prior to the start of exposure. An appropriate volume of insecticide solution in acetone was added to each beaker and then the exposure was started. As larvae in retreats did not attack each other, no cannibalism was observed in any beakers during the experiment. Toxicity tests using second or older instars were conducted under continuous room light ( $c a$. $2000 \operatorname{lux})$.

At $48 \mathrm{hr}$ after the start of exposure, the immobility of tested larvae was assessed by stereomicroscopic and visual observations. A larva was defined to be affected by insecticide when it did not respond to stimulations such as stirring of test solution (for first to third instars) or gently poking the abdomen or retreat (for fourth and fifth instars) with a glass pipette. The 48-hr median effective concentration (48-hr $\mathrm{EC}_{50}$ ) was calculated from immobility data on the basis of nominal concentrations using the logit model in the PROC PROBIT procedure 
Table 1. Conditions used in acute toxicity tests with each larval instar of Cheumatopsyche brevilineata

\begin{tabular}{|c|c|c|c|c|c|}
\hline Conditions & 1st instar & 2nd instar & 3rd instar & 4th instar & 5th instar \\
\hline Test design & \multicolumn{5}{|c|}{ Static (no renewal of the test solution) } \\
\hline Test duration and temperature & \multicolumn{5}{|c|}{$48 \mathrm{hr}, 20^{\circ} \mathrm{C}$} \\
\hline Dilution water & \multicolumn{5}{|c|}{ Dechlorinated and fitered $(0.22-\mu \mathrm{m}$ pores $)$ tap water } \\
\hline Food & \multicolumn{5}{|c|}{ No food supply } \\
\hline Number of test organisms & \multicolumn{5}{|c|}{20 Larvae at each concentration } \\
\hline Test vessel & $\begin{array}{c}\text { 48-well } \\
\text { polystyrene dish }\end{array}$ & $\begin{array}{l}\text { 24-well } \\
\text { polystyrene dish }\end{array}$ & $\begin{array}{c}\text { 12-well } \\
\text { polystyrene dish }\end{array}$ & $500 \mathrm{ml}$ glass beaker & $1000 \mathrm{ml}$ glass beaker \\
\hline Volume of test solution & $1.5 \mathrm{ml} /$ well & $2.0 \mathrm{ml} /$ well & $5.0 \mathrm{ml} /$ well & $200 \mathrm{ml} /$ beaker & $400 \mathrm{ml} /$ beaker \\
\hline Density of test organisms & 1 ind./well & $1 \mathrm{ind} . /$ well & 1 ind./well & 10 inds./beaker & $10 \mathrm{inds} . /$ beaker \\
\hline Acclimation & None & None & None & Overnight ${ }^{a)}$ & Overnight $\left.{ }^{a}\right)$ \\
\hline Bottom materials & None & None & None & Glass beads $^{b)}$ & Glass beads ${ }^{c)}$ \\
\hline Agitation of test water & None & $100 \mathrm{rpm}^{d)}$ & $100 \mathrm{rpm}^{d)}$ & $200 \mathrm{rpm}^{e)}$ & $300 \mathrm{rpm}^{e)}$ \\
\hline Photoperiod & $\begin{array}{c}24 \mathrm{hr} \text { of } \\
\text { continuous light } f \text { ) }\end{array}$ & & \multicolumn{2}{|c|}{ - $24 \mathrm{hr}$ of continuous room lighting } & \\
\hline Endpoint & & & nmobilization & & \\
\hline
\end{tabular}

${ }^{a)}$ To make larvae construct fixed tubular retreats with glass beads during acclimation. ${ }^{b}$ Consists of $1.5 \mathrm{~g}$ of fine beads $(0.6 \mathrm{~mm}), 5 \mathrm{~g}$ of medium beads $(4 \mathrm{~mm})$ and $5 \mathrm{~g}$ of large beads $(7 \mathrm{~mm}) .{ }^{c)}$ Consists of $3 \mathrm{~g}$ of fine beads, $5 \mathrm{~g}$ of medium beads and $18 \mathrm{~g}$ of large beads. ${ }^{d)}$ Agitating with a rotary shaker. ${ }^{e}$ Stirring with a magnetic stirrer. ${ }^{f)}$ Because hatched larvae swim toward light, they were illuminated continuously from beneath the test vessel with fluorescent light to avoiding trapping them at the water surface. ind.: individual.

of version 9.13 of the SAS software. ${ }^{18)}$ Normality of the control larvae was more than $95 \%$ in all experiments.

\section{Statistical analysis}

The equivalence of concentration-response curves for each instar between strains $\mathrm{M}$ and $\mathrm{K}$ was tested statistically using logistic regression (PROC LOGIST procedure) as described by Oris and Bailer. ${ }^{19)} \mathrm{EC}_{50}$ values of a given insecticide for each instar were compared between strains $\mathrm{M}$ and $\mathrm{K}$ using the confidence intervals test. ${ }^{20)}$ If $95 \%$ confidence intervals overlapped, we concluded that insecticide sensitivity was not statistically different between strains. All statistical analyses were performed using version 9.13 of SAS software. ${ }^{18)}$

\section{Results}

In both strains $\mathrm{M}$ and $\mathrm{K}$, first instar was the most sensitive and fifth instar was the least sensitive larval stage to all three in-

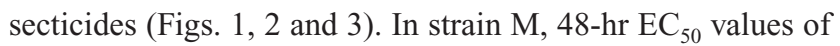
MEP were $6.23 \mu \mathrm{g} / 1$ (first instar) and $26.5 \mu \mathrm{g} / 1$ (fifth instar), increasing up to 4.3 times with larval growth (Fig. 1). The $\mathrm{EC}_{50}$ of BPMC increased up to 10.3 times, ranging from 9.48 $\mu \mathrm{g} / 1$ (first instar) to $91.9 \mu \mathrm{g} / 1$ (fifth instar) (Fig. 2). The $\mathrm{EC}_{50}$ of IMI ranged from $6.64 \mu \mathrm{g} / 1$ (first instar) to $37.9 \mu \mathrm{g} / 1$ (fifth instar) (5.7 times higher) (Fig. 3).

In strain $\mathrm{K}$, the $\mathrm{EC}_{50}$ value of MEP of fifth instar $(741 \mu \mathrm{g} / \mathrm{l})$ was 28.4 times higher than that of first instar $(26.1 \mu \mathrm{g} / 1)$ (Fig. 1). For BPMC, the $\mathrm{EC}_{50}$ of fifth instar $(291 \mu \mathrm{g} / \mathrm{l})$ was 36.9 times higher than that of first instar $(7.89 \mu \mathrm{g} / 1)$. The difference in sensitivity among instars, however, was less for IMI. The $\mathrm{EC}_{50}$ of the insecticide changed from 6.54 to $33.3 \mu \mathrm{g} / 1$ through larval growth (Fig. 3).

The concentration-response curves of MEP for each instar

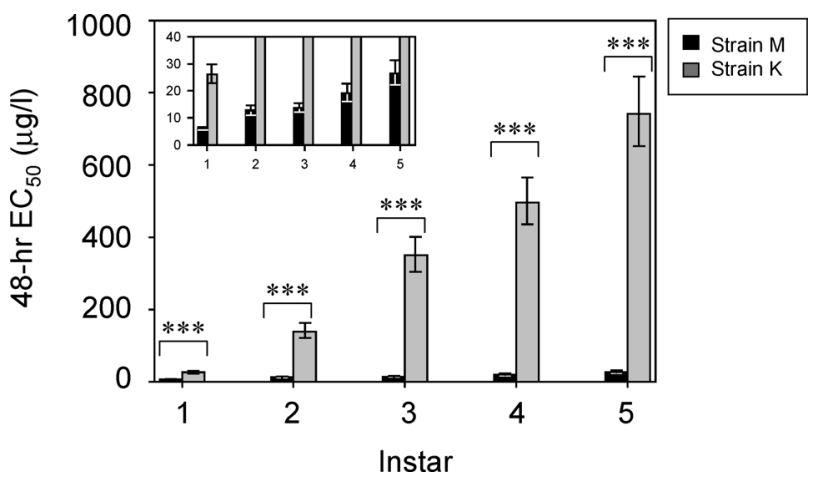

Fig. 1. Sensitivity of different larval stages of Cheumatopsyche brevilineata exposed to fenitrothion. Solid and gray bars represent 48-hr $\mathrm{EC}_{50}$ values of strains $\mathrm{M}$ and $\mathrm{K}$, respectively. Line bars indicate $95 \%$ confidence limits. The results in the low range of data for strain $\mathrm{M}$ are magnified in the inner graph. $* * *$ denotes a significant difference in concentration-response curves between strains $(P<0.001)$. 


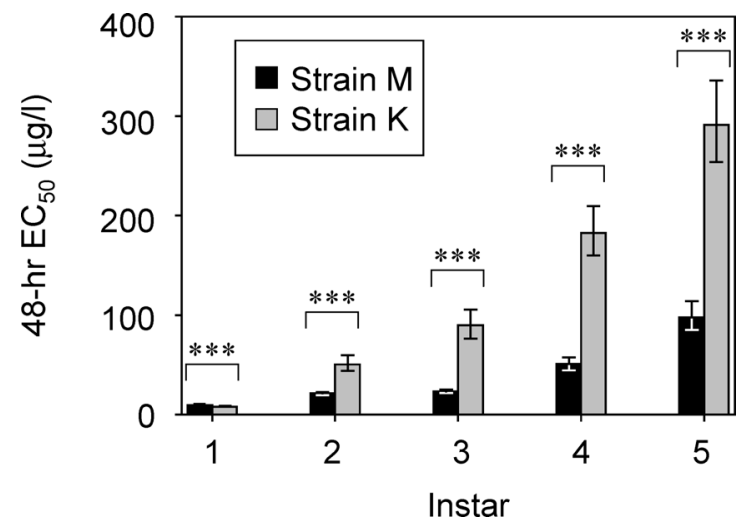

Fig. 2. Sensitivity of different larval stages of Cheumatopsyche brevilineata exposed to fenobucarb. Solid and gray bars represent 48$\mathrm{hr} \mathrm{EC}_{50}$ values of strains $\mathrm{M}$ and $\mathrm{K}$, respectively. Line bars indicate $95 \%$ confidence limits. $* * *$ denotes a significant difference in concentration-response curves between strains $(P<0.001)$.

differed significantly between strains $(P<0.001)$. Furthermore, 95\% confidence limits around 48-hr $\mathrm{EC}_{50}$ values of MEP for each instar did not overlap between strains $\mathrm{M}$ and $\mathrm{K}$ (Fig. 1). The difference in MEP sensitivity at the same larval stage between strains increased from 4.2 to 28 times through larval growth. These results suggested that larvae of strain $\mathrm{K}$ were more insensitive to MEP through larval growth than larvae of strain M. The concentration-response curves of BPMC differed significantly between strains through larval growth $(P<0.001)$. With the exception of first instar, 95\% confidence limits around 48-hr $\mathrm{EC}_{50}$ values of BPMC for each instar did not overlap between strains (Fig. 2). The $\mathrm{EC}_{50}$ of BPMC in strain $\mathrm{K}$ was similar to that in strain $\mathrm{M}$ at first instar but increased up to three times at fifth instar. These results suggested that strain $\mathrm{K}$ was significantly more insensitive to BPMC in second or later instars than strain M. In the case of IMI, the $95 \%$ confidence limits around $\mathrm{EC}_{50}$ values for each

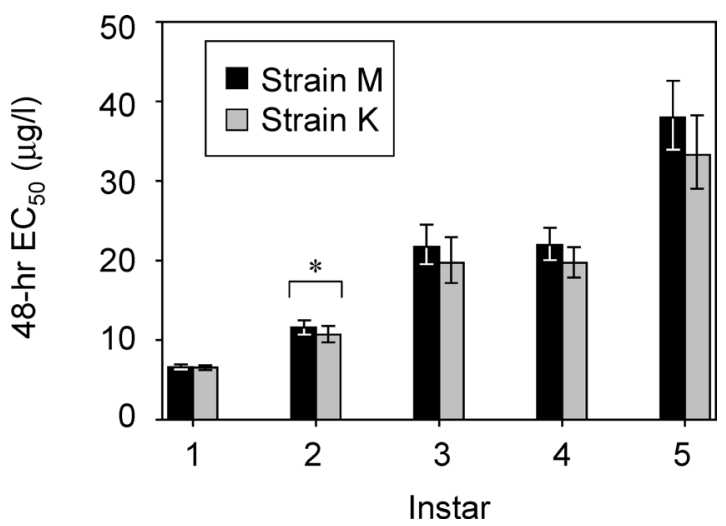

Fig. 3. Sensitivity of different larval stages of Cheumatopsyche brevilineata exposed to imidacloprid. Solid and gray bars represent 48-hr $\mathrm{EC}_{50}$ values of strains $\mathrm{M}$ and $\mathrm{K}$, respectively. Line bars indicate $95 \%$ confidence limits. $*$ denotes a significant difference in concentration-response curves between strains $(P<0.05)$. instar overlapped and the concentration-response curves for each instar were generally equivalent between strains except for the second instar $(P<0.05)$ (Fig. 3), suggesting no significant difference in sensitivity to IMI between strains $\mathrm{M}$ and $\mathrm{K}$.

\section{Discussion}

The earlier life stages of aquatic organisms are often the most sensitive to chemicals. ${ }^{2,4-6)}$ Stuijfzand et al. ${ }^{5)}$ reported that the LC50s of an organophosphate, diazinon, increased up to 84 times at fifth instar compared to the first instar of a hydropsychid caddisfly, Hydropsyche angustipennis. In our study, the first instar of $C$. brevilineata was found to be the most sensitive stage to the three insecticides, regardless of the mode of action.

In this study, a series of acute toxicity tests for each larval instar were conducted under different test conditions (Table 1). In the comparison of insecticide sensitivity of $C$. brevilineata among different instars, it is necessary to consider that the results of toxicity tests may be partially dependent on the test condition, such as the material of the test vessel and volume of the test solution. A preliminary study showed that the 48-hr $\mathrm{EC}_{50}$ of MEP for first instar did not differ significantly, regardless of the material of the test vessel (glass or polystyrene) and volume of the test solution (1.5 to $8 \mathrm{ml}$ per larva) (Ohtsu et al., unpublished data). Further investigations of other larval instars are required to assess the effect of test conditions on the results of toxicity tests.

One of the main determinants of the sensitivity of aquatic insects to insecticide is the insecticide uptake rate, defined as the insecticide concentration in tissue per unit time. ${ }^{21,22)}$ Buchwalter et al. ${ }^{22)}$ demonstrated that in the midge Chironomous riparius the difference in sensitivity among larval instars to an organophosphate, $\left[{ }^{14} \mathrm{C}\right]$ chlorpyrifos, was due primarily to the uptake rate difference, which was determined by differences in body size (i.e., surface area to volume ratio) during larval growth. In strain $\mathrm{M}$ of $C$. brevilineata, it seems reasonable to assume that the difference in uptake rate among larval instars is one of the mechanisms responsible for the change in sensitivity to the three insecticides during larval growth.

In addition to the mechanism, repeated exposure to paddy insecticides may explain the significant insensitivity to insecticides in later instars of strain K. The Kokura River is a tributary of the Koise River which flows through an extensive paddy region in the east and south of Mt. Tsukuba, Ibaraki Prefecture. MEP and BPMC has been detected in river water of the Koise River and its tributaries. ${ }^{23)}$ Although we did not monitor insecticide concentrations in river water of the Kokura River, populations of $C$. brevilineata may have been exposed repeatedly to paddy insecticides in the river over time. It is speculated that prolonged selection pressure by insecticides may have caused changes in the genetic background and insecticide sensitivity of populations in the river. The caddisfly population inhabiting a pesticide-contaminated 
river was found to be insensitive to MEP and BPMC. ${ }^{17,24)}$ Konno et al ${ }^{25)}$ revealed that the detoxification of fenitrooxon (the active metabolite of MEP) by binding protein is the primary MEP-insensitive mechanism of $C$. brevilineata. This insensitivity mechanism may be common in caddisfly populations living in pesticide-contaminated river because fenitrooxon-binding activity was observed in three geographically distant populations $;{ }^{25)}$ therefore, it is speculated that production of the binding protein is responsible for the insensitivity to MEP of strain K.

It has been shown that carboxylesterase acts as both a sequestering and hydrolyzing protein to detoxify carbamates in the peach-potato aphid Myzus persicae. ${ }^{26)}$ Yoo et al. ${ }^{27)}$ demonstrated that the major mechanism of resistance to BPMC in the brown phanthopper Nilaparvata lugens was insensitivity of $\mathrm{AChE}$ to the insecticide; however, the BPMC-insensitive mechanism of $C$. brevilineata remains to be clarified.

Sensitivity to IMI did not differ significantly between strains M and K. MEP, BPMC and IMI have been registered for use in Japan since 1961, 1968 and 1992, respectively. ${ }^{28)}$ IMI is commonly used in rice nursery box treatment, which is an application method to minimize pesticide runoff from paddy fields into rivers. The duration and intensity of the toxicological pressure of IMI may still not be sufficient for $C$. brevilineata populations in the Kokura River to develop insensitivity.

The response of an organism can differ among growth stages depending on the type of chemical. Shimada and Nozaki ${ }^{7)}$ reported that sensitivities to organophosphates, MEP and diazinon, decreased through larval growth of a limnephilid caddisfly, Nothopsyche ruficollis, whereas sensitivity to carbaryl, a carbamate insecticide, increased in older larval stages. The most sensitive life stage of $H$. azteca differed depending on the type of chemical. ${ }^{9)}$ The earliest age class ( 0 to 2 days old) of $H$. azteca was the least sensitive to diazinon but the most sensitive to alkylphenol ethoxylates among several age classes from zero to 2 days to 24 to 26 days old. ${ }^{9)}$ It is important to understand both the significance of different routes of uptake for different types of chemical and the physiology of an organism in order to predict differences in sensitivity among both species and growth stages. ${ }^{1)}$

Partial life-cycle tests will be useful tools for assessing the impact of chemicals on populations of aquatic organisms with a long life-span if these tests can be incorporated into a population dynamics model ${ }^{1,29)}$ In our laboratory culture of $C$. brevilineata, it took about 3 or more months to complete a life cycle. Thus, the full life-cycle toxicity test using this species will be complicated and require considerable time and effort to accomplish. The series of acute toxicity tests developed in this study could reasonably assess insecticide sensitivity during larval growth in both strains with different ecological backgrounds. These toxicity tests can be used as partial lifecycle toxicity tests and will trigger further ecotoxicological studies to assess the effects of paddy insecticides on popula- tion dynamics of $C$. brevilineata.

\section{Acknowledgments}

We especially thank Dr. Satoshi Fukushima (Yokohama Environmental Science Research Institute), who helped to collect the caddisflies. We are deeply grateful to Ms. Kayoko Hamaguchi, who helped maintain our caddisfly population. This work was supported in part by a Grant-in-aid (Hazardous Chemicals) from the Ministry of Agriculture, Forestry and Fisheries of Japan (HC-06-2212-2).

\section{References}

1) A. B. A. Boxall, C. D. Brown and K. L. Barrett: Pest Manag. Sci. 58, 637-648 (2002).

2) T. H. Hutchinson, J. Solbé and P. J. Kloepper-Sams: Chemosphere 36, 129-142 (1998).

3) D. W. J. Green, K. A. Williams and D. Pascoe: Arch. Environ. Contam. Toxicol. 15, 465-471 (1986).

4) A. V. Nebeker, M. A. Cairns and C. M. Wise: Environ. Toxicol. Chem. 3, 151-158 (1984).

5) S. C. Stuijfzand, L. Poort, G. D. Greve, H. G. van der Geest and M. H. S. Kraak: Environ. Toxicol. Chem. 19, 582-587 (2000).

6) A. H. Hyder, J. P. Overmyer and R. Noblet: Environ. Toxicol. Chem. 23, 2856-2862 (2004).

7) T. Shimada and T. Nozaki: Jpn. J. Environ. Toxicol. 3, 39-46 (2000) (in Japanese).

8) S. Hatakeyama and Y. Sugaya: Environ. Pollut. 59, 325-336 (1989).

9) S. A. Collyard, G. T. Ankley, R. A. Hoke and T. Goldenstein: Arch. Environ. Contam. Toxicol. 26, 110-113 (1994).

10) H. Nishimoto: Res. Bull. Aichi Agric. Res. Ctr. 28, 295-299 (1996) (in Japanese).

11) A. C. Alexander, J. M. Culp, K. Liber and A. J. Cessna: Environ. Toxicol. Chem. 26, 1726-1732 (2007).

12) M. Yagi and M. Sasakawa: Jpn. J. Environ. Entomol. Zool. 4, 1-10 (1992) (in Japanese).

13) A. Yokoyama, K. Ohtsu, T. Iwafune, T. Nagai, S. Ishihara, Y. Kobara, T. Horio and S. Endo: J. Pestic. Sci., 34, 13-20.

14) T. R. Fukuto: Environ. Health Persp. 87, 245-254 (1990).

15) K. Nagata, Y. Iwanaga, T. Shono and T. Narahashi: Pestic. Biochem. Phys. 59, 119-128 (1997).

16) Japan Plant Protection Association (ed.): "Noyaku Yoran 2007," Japan Plant Protection Association, Tokyo, 2007 (in Japanese).

17) M. Tada: Jpn. J. Environ. Toxicol. 5, 13-19 (2002) (in Japanese).

18) SAS Institute Inc: "SAS/STAT ${ }^{\circledR} 9.1$ User's Guide," SAS Institute Inc, Cary, NC, USA, 2004.

19) J. T. Oris and A. J. Bailer: Environ. Toxicol. Chem. 16, 22042209 (1997).

20) M. W. Wheeler, R. M. Park and A. J. Bailer: Environ. Toxicol. Chem. 25, 1441-1444 (2006).

21) D. B. Buchwalter, J. J. Jenkins and L. R. Curtis: Can J. Fish. Aquat. Sci. 59, 1315-1322 (2002).

22) D. B. Buchwalter, J. F. Sandahl, J. J. Jenkins and L. R. Curtis: Aquat. Toxicol. 66, 149-157 (2004).

23) S. Hatakeyama, T. Inoue and M. Tada: Jpn J. Environ. Toxicol. 2, 113-125 (1999). 
24) M. Tada and H. Shiraishi: Jpn. J. Limnol. 55, 165-170 (1994).

25) Y. Konno, S. Hatakeyama, Y. Sugaya and S. Fukushima: Appl. Entomol. Zool. 29, 113-116 (1994).

26) A. L. Devonshire and G. D. Moores: Pestic. Biochem. Phys. 18, 235-246 (1982).

27) J.-K. Yoo, S.-W. Lee, Y.-J. Ahn, T. Nagata and T. Shono: Appl.
Entomol. Zool. 37, 37-41 (2002).

28) Japan Plant Protection Association (ed.): "Noyaku Handbook 2005," Japan Plant Protection Association, Tokyo, 2005 (in Japanese).

29) C. Lopes, A. R. R. Péry, A. Chaumot and S. Charles: Ecol. Model. 188, 30-40 (2005). 